\title{
The Present Situation and Problems Analysis of Smart Community Nursing Service in Beijing
}

\author{
Ju HUANG \\ North China Electric Power University, China \\ 906756146@qq.com \\ Ju Huang
}

Keywords: Smart community, Aging population, Community nursing service, Home-based elderly care.

\begin{abstract}
Smart community will be the main trend of Beijing urban construction in the future. With the development of smart community in Beijing and the increasing number of it, it brings a convenient life to people. But to almost people, smart community still has many deficiencies, for example, it can't fulfill the requirement of care service, uneven nursing service quality, and unclear responsibility in care service, and low utilization of smart equipment for old people. Against the background of "Internet plus", "Online to Offline”, "Home-based elderly care" and "Aging population", these deficiencies are not only chances but also challenges. So the writer puts forward three aspects which include equipment, technology and top-down design to develop the smart community nursing service in Beijing.
\end{abstract}

\section{The Present Situation of Smart Community in Beijing}

Because of the appearance and development of new generation technology such as Internet of things, cloud computing, and the improvement of city information level, the global information technology develops quickly. Information technology plays a more and more important role in national economy. In 2009, IBM presented the idea "Smart City" and worked out a practicable business plan. Many developed countries have put forward a plan about smart city construction.

In order to lead the way in the competition of new generation technology, Chinese government proposed a strategy blueprint about smart city development in time. National Development and Reform Commission, Ministry of Industry and Information Technology, Ministry of Land and Resources and other five ministries issued a guideline promoting smart city healthy development in 2014. The guideline brought forth that a lot of unique smart city will be built till 2020. The role of these cities aggregation and radiation will greatly strengthen. Comprehensive competition advantages are going to significantly improve as well. In the aspects of Ensuring and improving people's livelihood, innovating social management and protecting network security will get remarkable result. ${ }^{[1]}$

As early as 2012, Beijing Municipal Government has provided Smart Beijing Action Program to promote development of Beijing information during the Twelfth Five-Year. The program pointed that the theme of information development in next ten years is Smart Beijing, and clearly set several goals like improving information equipment, setting up city management system and realizing digital life environment, and it also guided a direction for smart city's future.

At some point, smart city consists of some units like smart community which is an important part of smart city. Smart community emerged at a proper moment. For executing the documents such as Smart Beijing Action Program, the Guideline of Social Information Construction for the 12th Five-Year Plan in Beijing and the Suggestion of Social Information Construction for the 12th Five-Year Plan in Beijing, Beijing Municipal Government put forward the Suggestion of Beijing Smart Community Construction and the Standard of Beijing Smart Community. Smart community is defined as an organization using Internet of Things, cloud computing, mobile Internet and intelligent terminal realizes digitization, networked, intelligence, mutualism and collaboration in 
seven elements of residents' lives by the standard. The standard stipulated clear conditions to build and rate smart community, which is divided by bonding force and anticipation.

In 2016, there were 1672 smart communities built that is 58 percent of all communities in Beijing, and surpassed the goal of 1500 in Smart Beijing Action Program during the Twelfth Five-Year. All the smart communities were covering 3.66 million families and 9.69 million residents. There were also 43 streets full coverage of smart communities in whole city. ${ }^{[2]}$ Beijing will build 362 new smart communities in 2017. These present that smart community in Beijing is booming.

\section{The Background and Present Situation of Smart Community Nursing Service in Beijing The Increasing Number of Nursing Care Issues with Aging Population Growing}

Nowadays, aging population is growing rapidly, so Beijing Municipal Government is facing great pressure in nursing care. Till the end of 2015, Beijing has about 3.133 million registered people aged 60 or older, accounting for $23.4 \%$ of the registered population, ranked as the second oldest population in China. And the regular old residents in Beijing were about 3.405 million, accounting for $15.7 \%$ of the regular residents. The number of old people aged 60 or older grew about 500 per day, and aged 80 or older grew about 120. Beijing registered old people will be over 3.8 million and regular old residents will be over 4 million in 2020. [3]

The rate of labor supply decreasing and the rate of old people increasing worsen the burden of labors. The number of people paying social insurance decreasing and the number of old people increasing challenge the support capability of social security fund. More and more couples who don't have brother or sister have to support four parents, so they are stressful. These problems with aging population growing urge the government to find a solution.

\section{The Necessity of Nursing Care Provided by Smart Community}

Because of the close relationship between old people and community, a social service, known as home-based elderly care which bases on family and relies on community, came into being. At same time, nursing care as an important section of smart community in Beijing provides convenience for residents. Although home-based elderly care and smart community are two different concepts, they still have same requirements in nursing care. About $96 \%$ old people live their lives at home and community, while the rest $4 \%$ live at nursing care institutions. However, there are only 500 nursing care institutions and 50,000 old people live there, which can't satisfy the huge demands of nursing care in Beijing. So most old people in Beijing have to be taken care at home and community. The community should provide some necessary nursing services to old residents, so that elderly resident, especially disable old people, will be looked after properly.

\section{The Present Situation and Styles of Smart Community Nursing Service in Beijing}

Some smart communities install alarm buttons and gas alarms. They also provide free services such as cleaning, treating and hairdressing. The old people losing their child can get help from several people in the activity of smart community. Long time care services toward old people exist in smart community. Smart community may cooperate with university that students teach old people to use WeChat. A lot of social work offices are sponsoring smart communities as well. The volunteers of smart community working with nursing institutions send meals and vegetable to old people. Community health center train the staffs in smart community in order to help the old people in times of emergencies.

There are four levels in home-based elderly care system of Beijing. In city level, a nursing service system will be set up by Beijing Aging Office. In district level, nursing service guideline center will be built. In street level, nursing service center will be constructed. In community level, nursing service station will exist. For someone elderly, the nursing service center in street and the nursing service station in community are main suppliers in elderly care service. So the situations of 
nursing service center and nursing service station are the important evaluating indicators in researching the level of smart community nursing service in Beijing.

\section{The Nursing Service Center of Beijing}

The street provides the ground and houses for the nursing service center, and outsources the service to relevant community service corporations. This nursing service center mainly has two services that are full-time nursery and day care. The full-time nursery usually faces to the disabled or half-disabled elders, while the day care usually faces to the elders can take care themselves. Doctors, nurses, dietitians, psychological consultants and the care workers with special skills stay at the center all the time. Old people attain not only the physical care such as medical service and recovery service, but also the spirit care like psychological counseling. The services of some nursing service center are more high-end. For example, the nursing service center in Anzhen Street relies on their good location, near the Anzhen Hospital. If elder feels bad suddenly, they can send the elder to hospital on time. The center also cooperates with Anzhen community health station, which is that the center provides real-time feedback of elderly patients' situation to the station through internet. Nursing service centers strictly regulate the visiting hours, and in the other time, centers will be closed, in order to keep elders safe.

\section{The Nursing Service Station of Beijing}

The street also provides the ground and houses for the nursing service station, and outsources the service to relevant community service corporations. Beijing Municipal Government invests about 300 thousand to every nursing service station, which doesn't include the money used to buy services. The services in nursing service station are different with those in nursing service center, which are home-based such as day care, call service, meal service, health guideline, psychological care, cultural entertainment activities, etc. The workers in the station are the staffs of training institution, community volunteers and the nurses of nursing institutions. Elders who purchase the services have the ability to take care of themselves and live within $1 \mathrm{~km}$ around the nursing service station. Meal service is a unique service provided by the station. Self-service selling meal machine of smart nursing is equipped in every station, which can sell ready-made nutritional meals to elders through technology of cold chain and heating. The prices of meals arrange from 3RMB to 25RMB that are very affordable. Elders swipe Smart Nursing Service Card to buy meals in the Platform of Self-service Selling Meal. The whole process of meal service is intelligent.

\section{The Differences between the Nursing Service Center and Station}

The nursing service station is usually close to the nursing service center and shows a pattern which is stations around a center. Because center has professional employees, equipment and enough space, stations can get resource from the center when they need to provide professional services. In some ways, the nursing care station has a few similar services with the nursing care center. Their service places are different, the former's place is at the homes of residents and the center, while the latter's place is only at the center. However, a bigger difference between the center and the station is that the former faces to the elders have good financial ability and poor self-care ability, while the latter faces to the elders have normal even poor financial ability and good self-care ability.

\section{The Problems in the Smart Community Nursing Service of Beijing and Solutions}

\section{Low Utilization of Smart Nursing Service Equipment for Elders}

With human body function ageing, old people can't master the way of using high-tech equipment, so the equipment have low utilization. The smart electronic assistant terminals such as electronic payment terminal and self-service selling meal machine, may go wrong and need a long time to be repaired. These two situations make elders' lives are not convenient enough.

To solve these problems, staffs of community or community service corporations should help old people in the peak using equipment and teach old people how to use the equipment. The periodical 
overhaul and maintenance should be taken by someone find wrong equipment and repair equipment in time, in order to ensure elders' qualities of life.

\section{The Responsibility Problems of Elders' Lives in the Center and Station}

When elders are taken care in the institution, there must be responsibility issues in the services. Government asks stations to set up risk protection mechanism, buy relevant comprehensive responsible insurance, sign service contract with long time consumers, show safety instruction and encourage old people to purchase accident insurance. ${ }^{[4]}$ However, there also some risks can't be avoided.

So the nursing service center and station need to put elders' safety at first, try to avoid contradiction appearance and clear divide the responsibility between institutions and elders when they provide services. Government should work out relevant laws to help and protect both elders and institutions, and reduce contradiction.

\section{Uneven Nursing Service Quality in Smart Community}

The nursing services in smart community are just at the beginning; so many factors are still deficient. Although Beijing Municipal Government published the designing and servicing standards of community nursing service station, this is not enough. The government should provide feedback platform of smart community nursing service to find problems in the service, inspect each community regularly and set up practical supervision mechanism to ensure the nursing service quality. Professional staffs are the important section of nursing service, so institutions should raise their staffs professional ethics and competence to standardize the service procession.

\section{Imbalance between Supply and Demand in Nursing Service}

Nowadays, the number of nursing institutions in Beijing smart communities is short, which can't satisfy the care demands of residents. In the end of 2016, there are more than 200 nursing service centers covering 63\% streets in whole city, basically realize full coverage of elders care demands. But until 2016, there are only 150 nursing service stations in Beijing, and more than 200 stations planned to build. To most residents, they can't afford the fee of nursing service center, so they prefer to the nursing service station to solve their care problems.

If an old man chooses to be taken care by a center, he will pay about 3000RMB for a bed, about 1000RMB for meals, which means he has to pay about 4000RMB monthly. Besides these, he has to pay 30000-50000RMB for deposit and about 1500RMB for settlement fee. If he chooses home-based nursing service, he will only pay for the service he buys at the station. Meal service need 3-25RMB, clean service need 25RMB per time, home bath service need 60RMB per time, even day care only need 60RMB per day. Home-based nursing service is more economic than nursing service of institutions, so nursing service station should be popularized in community when nursing service centers are basically full coverage, so that old people can enjoy high quality of nursing service at their homes.

\section{The Ideas of Completing Beijing Smart Community Nursing Service}

\section{Improvement of Nursing Equipment}

In the background of aging population, smart communities try their best to install convenient equipment such as stair railing, elevator and stair lift to help elders get out. They should also install smoke alarm, alarm button and other smart furniture in elder's home to ensure elder safe. The smart community should deliver the number of elderly mobile phones and tracing bracelets, and increase the utilization of them. As rapid development of technology and more high technology facilities, we should pay more attention to update nursing equipment and improve elders' well-being.

\section{Renewing Technological Means of Nursing Service}

Because of Internet Plus and online to offline, smart community should combine internet into elder daily life and develop different platforms so that old people can solve many problems online. For 
example, a health service platform can record elders' body conditions and their common medicines of chronic diseases. According to the records, community health service center can prepare unique medicine for elders, so elders get medicines without going to hospitals. Online shopping platform is also a good idea for old people who can order the vegetables and commodity without getting out which will be delivered on next day.

\section{Completion of Government Top-Level Design}

Nursing service as a smart community function needs a lot of labors and materials, so government can only be a leader and social institutions like non-profit organizations and companies will be main parts.

Firstly, companies usually provide service based on their rules, and government doesn't clear the standards in some services, so the whole industry is in chaos. Each company has their own platform, which brings difficulties to the supervision for government. How to deal with the relation between government and company and the relation between two companies is a problem need to be deeply researched.

Secondly, the government-leading and company-contracting service style costs too much money of old people. Even government gives subsidies to old people, it is still a big expense for them. So other nursing service styles should be encouraged to develop. For example, community volunteering service team and community family neighborhood help service are the styles that the younger old can help elder old to accumulate the service time which can be exchanged for the time helped by others.

Finally, government should pay attention to spirit care in nursing service. In some ways, elders need to be companied rather than have a convenient life. Spirit care is more important to empty-nesters and the elders lose their children. So we should focus on the construction of spirit care activities in the future of smart community nursing service.

\section{Summary}

With aging population growing, nursing care issues becomes hot. Home-based nursing service style is appearance, which includes nursing service center and nursing service station. As nursing service centers are basically full coverage in the future, nursing service station should be popularized in community. Nursing service in smart community still has many deficiencies, for example, it can't fulfill the requirement of care service, and unclear responsibility in care service, uneven nursing service quality and low utilization of smart equipment for old people. Government should solve problems from several aspects such as updating equipment, regulating rules, training professional staffs and institution construction. Completing infrastructure construction, technological means and top-level design will help Beijing smart community nursing service develop.

\section{Reference}

[1] The notice about printing the guideline of helping smart city healthy develop (In Chinese)http://www.sdpc.gov.cn/gzdt/201408/t20140829_624003.html

[2] There are 1672 star level smart communities in Beijing.(In Chinese)http://zhengwu.beijing.gov.cn/gzdt/bmdt/t1420262.htm

[3] The plan of aging industry development in 13th Five-Year of Beijing (In Chinese)http://zhengwu.beijing.gov.cn/gh/dt/t1466417.htm

[4] The policy interpretation of equipment design and service standards in community nursing service station (In Chinese)http://zhengce.beijing.gov.cn/library/192/34/738532/83731/index.html 